\title{
Non-communicable diseases and reproductive health in sub-Saharan Africa: bridging the policy-implementation gaps
}

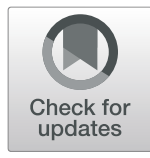

\author{
Sanni Yaya ${ }^{1,2^{*}}$, K. Srikanth Reddy ${ }^{3}$, José M. Belizán ${ }^{4}$ and Verónica Pingray ${ }^{4}$
}

Sub-Saharan Africa (SSA) region is a home for over one billion population distributed in 46 different countries. Over the decades, this region has confronted with high disease burden accounting around $24 \%$ of the global disease burden [1]. Traditionally, communicable diseases such as HIV, TB, and Malaria have long been the most prominent contributors to the disease burden. However, in the last two decades, the region has witnessed an epidemiological transition to non-communicable diseases (NCDs) [2]. Around $80 \%$ of all NCDs deaths occur in low and middle-income countries. It is projected that by 2020 , NCDs will account for $27 \%$ of mortality in SSA [3]. Majority of NCDs related deaths can be prevented by addressing the common modifiable risk factors for NCDs include tobacco use, physical inactivity, the harmful use of alcohol, and unhealthy diet [4].

The NCDs and reproductive health morbidity and mortality, has become a significant part of the disease burden in the region requiring a rethink on policy prioritisation and implementation to minimise the burden.

The WHO defines reproductive health as a "state of complete physical, mental and social well-being and not merely the absence of disease or infirmity, in all matters relating to the reproductive system and its functions and processes." This implies that people are able to have a satisfying and safe sex life and that they can reproduce and the freedom to decide if, when, and how often to do so [5]. However, reproductive health among women was often constrained by socio-cultural and economic factors across the societies, particularly in SSA. The access to abortion and contraception are severely restricted, contributing to high maternal mortalities and poor sexual and reproductive health outcomes [6-9]. Reproductive and maternal morbidities increase the risk of maternal

\footnotetext{
* Correspondence: sanni.yaya@uottawa.ca

${ }^{1}$ School of International Development and Global Studies, Faculty of Social Sciences, University of Ottawa, Ottawa, Canada

${ }^{2}$ The George Institute for Global Health, The University of Oxford, Oxford, UK Full list of author information is available at the end of the article
}

mortality, stillbirth, neonatal death. Women facing pregnancy related complications are predisposed to immediate and long-term disabilities and infertility as well as adverse psychological and socio-economic consequences. SSA region faces high burden of maternal mortality, stillbirth and neonatal mortality rates [10]. In 2015, twothirds of all maternal deaths worldwide occurred in SSA (546 maternal deaths per 100,000 live births [11]. SSA women in reproductive age (15-49 years) have low contraceptive prevalence rate (28\%), and about half of them do not receive four or more antenatal check-ups (54\%), and do not give birth in health facilities (52\%). Further, adolescent girls and young women in the region face high risk of unintended pregnancies, sexually transmitted infections, HIV, and exposure to violence [12]. Further, 244,000 infants in the region annually become infected with HIV during pregnancy and delivery (115, $000)$ or breast-feeding $(129,000)$ [13].

The unmet needs of sexual and reproductive health services among SSA women are coupled with the rising burden of non-communicable diseases. NCDs account for almost $65 \%$ of women's deaths globally, and the majority of these deaths occur in LMICs and are premature. In recent years, NCDs among women of reproductive age has doubled in many African countries [14]. Also, there are established linkages between NCDs and reproductive health. Several NCDs risk factors adversely affect the reproductive health of women. For example, obesity, CVDs, hypertension, hyperglycemia, and gestational diabetes predispose pregnant women at higher risk of menstrual problems, hypertension in pregnancy, caesarean sections, post-natal complications and maternal mortality [10]. Obesity also increases the odds of developing CVDs and cancers in women $[15,16]$. In a recent study, the prevalence of obesity across 32 Sub-Saharan African countries ranged from $1.1 \%$ in Madagascar to $23.0 \%$ in Swaziland [17]. A study shows that that women at the beginning of pregnancy $73.7 \%$ and $60.2 \%$ women in 
South Africa and Zimbabwe, respectively started their pregnancy with BMI above normal $(\mathrm{BMI} \geq 25)$ [18].

Epidemiological, clinical and animal studies have shown the modelling effect of fetal life on NCDs diseases of adult life, like hypertension, coronary heart disease and diabetes [19]. Furthermore, nutrients restriction during fetal life have shown higher blood pressure in the progeny. Animal studies have shown that protein restriction and calcium restriction during pregnancy involved hypertension of the progeny [20]. In humans, calcium supplementation during pregnancy involved a reduction of hypertension of children whose mothers were supplemented in comparison with a placebo group [21]. In a previous mentioned study done in South Africa and Zimbabwe the prevalence of inadequate micronutrient intake from food sources was high in both countries. For the most basic micronutrients like iron, calcium, folate and zinc, the percentage of women below requirements was above $90 \%$ in both countries [18].

Further, research suggests that obesity is linked to polycystic ovary syndrome (PCOS) in women. Moreover, obese women with PCOS have worse metabolic and reproductive outcomes [22]. The hypertensive disorders of pregnancy is one of the major cause of maternal deaths and stillbirths in the region [10].

African Union (AU) is at the forefront of shaping the national health priorities including women and child health. The AU, despite being the first to develop African Charter of Human and People's Rights on the Rights of Women in Africa that mandates state provision of comprehensive reproductive and sexual health services, is yet to be a reality and achieve the objective [23]. Building on Millennium Development Goal's (MDGs) progress on reducing maternal and child mortality and malnutrition, combating infectious diseases, an updated Global Strategy for Women's and Children's Health (2016-2030) was launched in 2016 [24, 25]. This universal and equity-based strategy aims to end preventable deaths among women by reducing global maternal mortality to less than 70 per 100,000 live births and reduce by one-third premature mortality from NCDs and promote mental health and well-being. The reproductive health policies must be in alignment with this global strategy to minimize the mortalities due to NCDs risk factors linked to reproductive health. And also, to optimize better sexual and reproductive health in the SSA.

At the individual level, prevention and continuum of care approach through "life-course" are essential for the prevention of NCDs. While most NCD related health outcomes cause morbidity and mortality during adulthood, exposure to risk factors begins early in life, and these behaviours often get established for the lifetime. WHO recommends that NCD prevention and control measures to consider health and social needs and reduce exposure to risk factors at all stages of the life course. Similarly, improving reproductive health outcomes calls for a comprehensive understanding of women's health throughout the life course. The global strategy for women's health adopts an integrated life course approach and underscores the need for investment in child and adolescent health and development [24].

At the systemic level, a comprehensive approach requires multipronged strategies focussing on prevention within primary care through community-based programs, health promotion, and cost-effective policies that target the whole population as well as high-risk individuals. Both NCDs and reproductive health thus needs to be addressed through both "population-based" and "high-risk individual" based approaches to empower individuals and populations to make healthier choices and access to health services. The global strategy recommends integrating NCDs prevention and treatment with women's, children's, and adolescents' health care [24, 25]. The population-level approaches include increasing awareness, creating a conducive environment and instituting public health policies while high-risk individual-level approaches include early diagnosis and management and treatment of disease and need to integrate into the health systems in SSA.

At the policy level, various bodies have emphasised the need for a collective response towards addressing health issues as it cuts across the sectors. The WHO has emphasized that effective NCD prevention and control require "health-in-all policies and whole-of-government approaches" across sectors, involving a range of ministries outside health such as health, agriculture, communication, education, employment, social welfare, social and economic development, sports, trade and industry transport, urban planning and others. Similarly, Global Strategy for Women's and Children's Health also emphasise the adoption of a multi-sectoral approach to develop and monitor interventions outside the health sector and asserts the countries to build governance mechanisms and capacity to facilitate multisector actor and cross-sector collaborations [25].

\section{Conclusion}

Most risk behaviours for NCDs and reproductive health are modifiable, and the related morbidity and mortality is preventable. Yet, the progress is largely determined by socioeconomic, demographic, political factors. Strengthening national policies, health systems, country-level surveillance, and monitoring systems, and creating sustainable partnerships and advocacy are key strategies towards addressing these health issues. However, implementation gaps remain contributing not only NCDs mortality, but also reproductive health. Identification of common risk factors and linkages among the NCDs and reproductive, would help intersectoral action and 
integration of health care services for the prevention of mortalities in respective sub-Saharan African counties. Such an effort, while contributing to better health outcome in region, also help accelerating the Sustainable Development Goals and targets, particularly SDG 3.4, 3.6, 3.7 and SDG11.2. Therefore, the journal encourages global public health scholars, particularly from subSaharan African countries to reflect upon these considerations and submission of manuscripts.

\section{Authors' contributions}

SY and KSR conceptualized and wrote the initial draft. JB and VP provided comments and edits. All authors commented on the first draft and signed off on the final version.

\section{Competing interests}

Sanni Yaya and José M. Belizán are Editors-in-Chief of Reproductive Health.

\section{Author details}

${ }^{1}$ School of International Development and Global Studies, Faculty of Social Sciences, University of Ottawa, Ottawa, Canada. ${ }^{2}$ The George Institute for Global Health, The University of Oxford, Oxford, UK. ${ }^{3}$ Bruyere Research Institute, University of Ottawa, Ottawa, Canada. ${ }^{4}$ Department of Mother and Child Health Research, Institute for Clinical Effectiveness and Health Policy (IECS-CONICET), Buenos Aires, Argentina.

Published online: 23 January 2020

\section{References}

1. International Finance Corporation. World Bank Group. Health and Education. 2019; Available at: https://www.ifc.org/wps/wcm/connect/REGION_EXT_ Content/IFC_External_Corporate_Site/Sub-Saharan+Africa/Priorities/Health+ and+Education/. Accessed 30 Dec 2019.

2. Gouda HN, Charlson F, Sorsdahl K, Ahmadzada S, Ferrari AJ, Erskine H, et al. Burden of non-communicable diseases in sub-Saharan Africa, 1990-2017: results from the global burden of disease study 2017. Lancet Glob Health. 2019;7(10):e1375-87.

3. Juma PA, Mohamed SF, Matanje Mwagomba BL, Ndinda C, MapaTassou C, Oluwasanu M, et al. Non-communicable disease prevention policy process in five African countries. BMC Public Health. 2018; 18(Suppl 1):961-018-5825-7.

4. World Health Organization. Noncommunicable diseases country profiles 2018. Geneva: World Health Organization; 2018.

5. World Health Organization. Health topics: Reproductive health. 2019; Available at: http://origin.who.int/topics/reproductive_health/en/. Accessed 30 Dec 2019.

6. Hall KS, Manu A, Morhe E, Dalton VK, Challa S, Loll D, et al. Bad girl and unmet family planning need among sub-Saharan African adolescents: the role of sexual and reproductive health stigma. Qual Res Med Healthc. 2018; 2(1):55-64.

7. Alemayehu B, Addissie A, Ayele W, Tiroro S, Woldeyohannes D. Magnitude and associated factors of repeat induced abortion among reproductive age group women who seeks abortion Care Services at Marie Stopes International Ethiopia Clinics in Addis Ababa, Ethiopia. Reprod Health. 2019; 16(1):76-019-0743-4.

8. Harries J, Orner P, Gabriel M, Mitchell E. Delays in seeking an abortion until the second trimester: a qualitative study in South Africa. Reprod Health. 2007:4:7-4755-4-7

9. Vallely LM, Homiehombo P, Kelly-Hanku A, Whittaker A. Unsafe abortion requiring hospital admission in the Eastern Highlands of Papua New Guinea--a descriptive study of women's and health care workers' experiences. Reprod Health. 2015;12:22-015-0015-x.

10. Alliance for Maternal and Newborn Health Improvement (AMANHI) mortality study group. Population-based rates, timing, and causes of maternal deaths, stillbirths, and neonatal deaths in South Asia and subSaharan Africa: a multi-country prospective cohort study. Lancet Glob Health. 2018;6(12):e1297-308.
11. World Health Organization. Trends in maternal mortality: 1990 to 2015 : estimates by WHO, UNICEF, UNFPA, World Bank Group and the United Nations Population Division. ISBN 978924156514 1. 2015.

12. Naidoo K, Adeagbo O, Pleaner M. Sexual and reproductive health needs of adolescent girls and young women in sub-saharan africa: research, policy, and practice. SAGE Open. 2019;9(3):1-3.

13. Singh S, Darroch J, Vlassoff M, Nadeau J. Adding It Up: The Benefits of Investing in Sexual and Reproductive Health Care. New York: The Alan Guttmacher Institute and the United Nations Population Fund; 2004. p. 30.

14. Yaya S, Uthman OA, Ekholuenetale M, Bishwajit G. Socioeconomic inequalities in the risk factors of noncommunicable diseases among women of reproductive age in sub-saharan Africa: a multi-country analysis of survey data. Front Public Health. 2018;6:307.

15. Kapur A. Links between maternal health and NCDs. Best Pract Res Clin Obstet Gynaecol. 2015;29(1):32-42.

16. Nkoka O, Ntenda PAM, Senghore T, Bass P. Maternal overweight and obesity and the risk of caesarean birth in Malawi. Reprod Health. 2019;16(1): 40-019-0700-2.

17. Yaya S, Ekholuenetale M, Bishwajit G. Differentials in prevalence and correlates of metabolic risk factors of non-communicable diseases among women in sub-Saharan Africa: evidence from 33 countries. BMC Public Health. 2018;18(1):1168-018-6085-2.

18. Cormick G, Betran AP, Harbron J, Dannemann Purnat T, Parker C, Hall D, et al. Are women with history of pre-eclampsia starting a new pregnancy in good nutritional status in South Africa and Zimbabwe? BMC Pregnancy Childbirth. 2018;18(1):236-018-1885-z.

19. Barker DJ, Winter PD, Osmond C, Margetts B, Simmonds SJ. Weight in infancy and death from ischaemic heart disease. Lancet. 1989;2(8663):577-80.

20. Langley-Evans SC, Phillips GJ, Jackson AA. In utero exposure to maternal low protein diets induces hypertension in weanling rats, independently of maternal blood pressure changes. Clin Nutr. 1994;13(5):319-24.

21. Belizan JM, Villar J, Bergel E, del Pino A, Di Fulvio S, Galliano SV, et al. Longterm effect of calcium supplementation during pregnancy on the blood pressure of offspring: follow up of a randomised controlled trial. BMJ. 1997; 315(7103):281-5.

22. Lim SS, Norman RJ, Davies MJ, Moran LJ. The effect of obesity on polycystic ovary syndrome: a systematic review and meta-analysis. Obes Rev. 2013; 14(2):95-109.

23. Ngwena CG. Protocol to the African charter on the rights of women: implications for access to abortion at the regional level. Int J Gynaecol Obstet. 2010;110(2):163-6.

24. Kuruvilla S, Bustreo F, Kuo T, Mishra CK, Taylor K, Fogstad H, et al. The global strategy for women's, children's and adolescents' health (2016-2030): a roadmap based on evidence and country experience. Bull World Health Organ. 2016;94(5):398-400.

25. High-Level Working Group on the Health and Human Rights of Women, Children and Adolescents. World Health Organization. Leading the realization of human rights to health and through health. Report of the High-Level Working Group on the Health and Human Rights of Women, Children and Adolescents. Geneva: World Health Organization; 2017.

\section{Publisher's Note}

Springer Nature remains neutral with regard to jurisdictional claims in published maps and institutional affiliations.

\section{Ready to submit your research? Choose BMC and benefit from:}

- fast, convenient online submission

- thorough peer review by experienced researchers in your field

- rapid publication on acceptance

- support for research data, including large and complex data types

- gold Open Access which fosters wider collaboration and increased citations

- maximum visibility for your research: over 100M website views per year

At BMC, research is always in progress.

Learn more biomedcentral.com/submissions 